\title{
LOS SERVICIOS DE SEGURIDAD SOCIAL EN FUNCION DE LOS PROGRAMAS DE SALUD PUBLICA EN LOS PAISES DE LATINO-AMERICA
}

Carlos Quirós, Federico Bresani S., Dámaso Gonzales R., Francisco Pedraza F., Armando Petrozzi G., Enrique Rubín de Celis T., Alejandro Sotelo B., Arturo Vasi P., Otoniel Velasco F., Milenko Zlatar S.

Aspectos generales de la Seguridad Social y los servicios de salud en América Latina

Para aliviar los estados de necesidad de las clases económicamente débiles, resultantes de una situación emergente que incapacita lemporal o definitivamente desde el punto de vista económico, la sociedad estableció servicios de índole caritativo, destinados fundamentalmente a la recuperación de la salud de los indigentes, y que se denominaron, genéricamente, Beneficencias, creadas por las clases pudientes, como una manifestación de solidaridad humana.

Paulatinamente las sociedades fueron reclamando la atención de sus estados de necesidad como un derecho, cuya satisfacción se consideró una obligación de los Estados. Como una respuesta a la creciente demanda de derechos sociales se empieza a dictar dispositivos legales, dispersos e inconexos, que beneficion desigualmente a los distintos grupos sociales. Tales son, a manera de ejemplo, las legislaciones sobre beneficios de cesantía, jubilación y otras pensiones, para emplecdos públicos; los dispositivos legales para empleados particulares, accidentes de trabajo, elc.

Posteriormente se creyó necesario institucionalizar la asistencia de los estados de necesidad, mediante los actuales sistemas de seguridad social. 


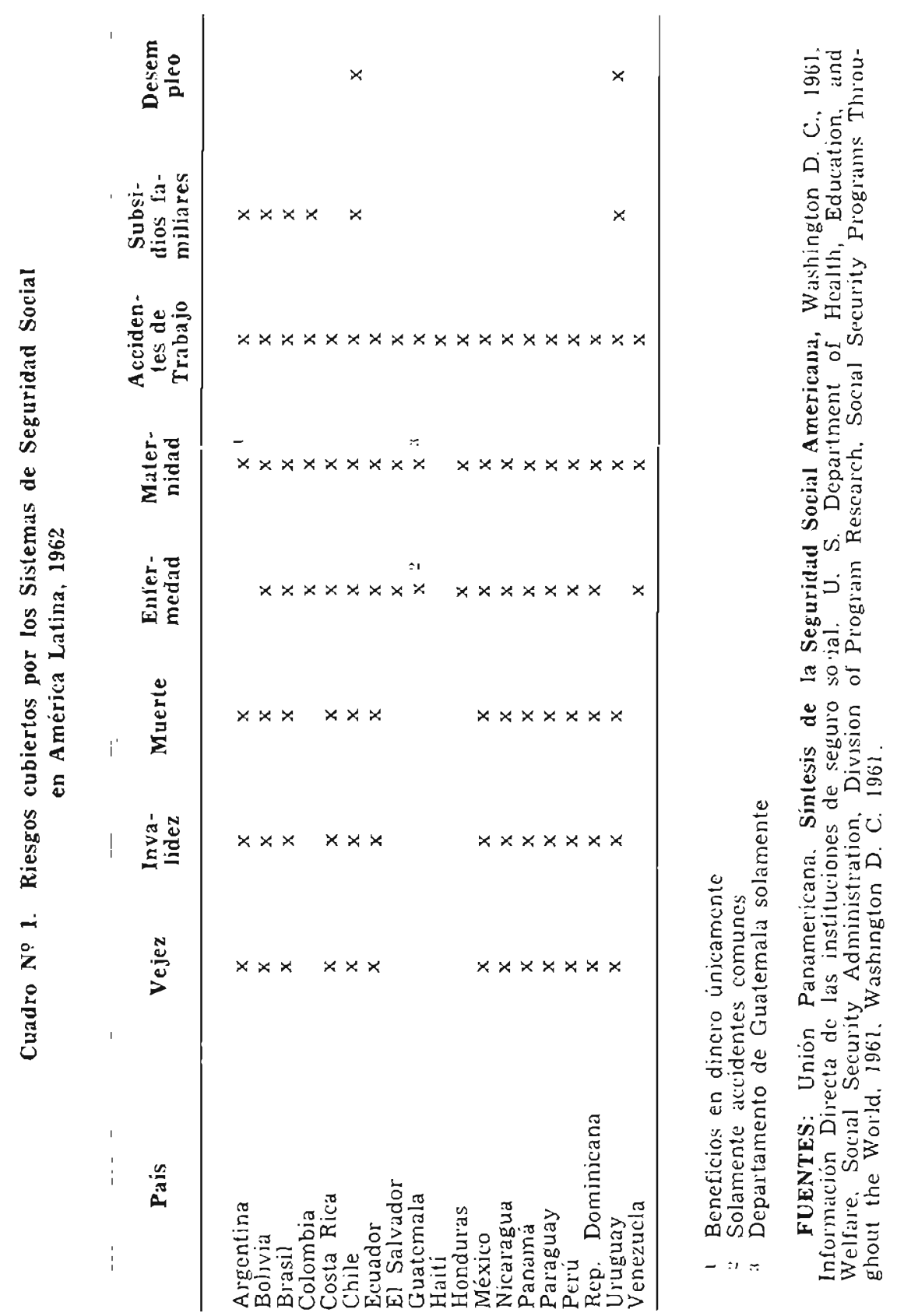


La Seguridad Social, como institución, cubre diversos riesgos que pueden reunirse en dos grandes grupos: Inmediatos y Tardíos. Los primeros son los de Enfermedad y Maternidad, los segundos son los de Invalidez, Vejez, Muerte y otros.

Los riesgos de Enfermedad y Maternidad, históricamente, han constituido materia de preferente atención por las sociedades que, para tal fin, crearon los hospitales de Beneficencia, instituciones caritativas, donde los servicios prestados eran gratuitos. Con el correr del tiempo las técnicas de la atención médica se van perfeccionando y haciéndose más costosas, tanto que las Beneficencias se ven incapacitadas para sufragar el gasto de una eficiente atención médica. Simultáneamente las masas reclaman la atención de su salud como una obligación del Estado.

En América Latina la seguridad social reviste formas variables de país a raís. En 18 países se cubren los riesgos de entermedad y malernidad y en 13 los de invalidez, vejez y muerte; en tanto que sólo 6 olorgan subsidios famíliares y en 2 hay cobertura del riesgo de desempleo. Cuadro No 1.

Se estima que en la actualidad sólo hay 15,000,000 de trabajadores cubiertos por los seguros sociales, lo que representa aproximadamente el $25 \%$ de la población económicamente activa. Cuadro No 2 .

Las poblaciones rurales están prrcticamente excluidas del sistema, así como los grupos de elsvados ingresos de las coleclividades, lo que representa injustos defectos de cobertura y financiamiento, respectivamente.

En casi todos los paises de América Latina, por lo menos en teoría, el Gobierno contribuye al sostenimiento del seguro social, en el entendido que el sistema tiene carácter universal, desde que la cuota estatal proviene de los contribuyentes de toda la colectividad y los benelicios debミrían concederse universalmente a toda la población y no sólo a algunos grupos que resultan privilegiados.

De acuerdo con informaciones de la OEA, la mayoría de países lalinoamericanos confronta el problema de incapacidad tinanciera para extender al campesinado sus sistemas de seguridad social, especialmente en el campo de las prestacionss de salud, las que, por otra parte, son puramente de tipo reparativo. Es bien sabido que la medicina reparativa, debido al acelerado progreso tecnológico, experimenta una elevación creciente de sus costos de opæración y es ésta la razón fundamental por la que el sistema no puede expandirse. 


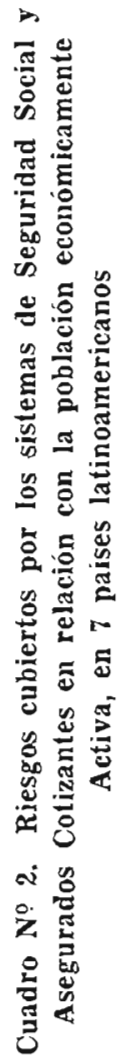

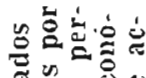

สํㅇㄹㄹ

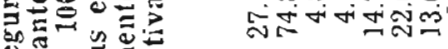

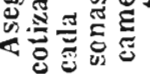

宽离高 บัธู ชृ 5 등 co.

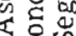
氺 $\ddot{0}=$

ชิ 象 สิ $\Xi$ ค.

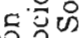
氙

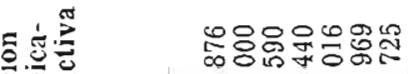
Дํㅐ욨 $N \quad \sim N$ 드요 ๑ ㅇํำ ฮ웡 可 ○े 뇽 利莕。

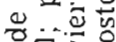
월 苍㟔。 ฮิ่

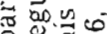
요의 口。 i் $\exists$ 范 ․ㅡㄹ요요 롤영 动 ह. है⿴囗十 电电 ह 웜 ब

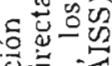

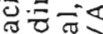

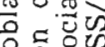
ค:ㅇํ유 两

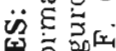
됭 之绾

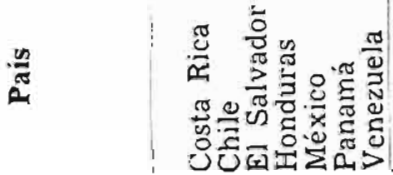


Por otra parte, los sistemas de seguridad social de América Latina, han sido forjados en el molde del Seguro Social de los países desarrollados de Europa, (donde hay un nivel de ingreso elevado y su disribución es menos desigual), e introducidos sir tener en cuenla el nivel de clesarrollo de la economia, lo que en última instancia origina que no hayan adquirido una maycr cobertura y que sus efecios en la distribución del ingreso tengan carácter regresivo.

Además de los denominacios Seguros Sociales, en América Latina exislen otras entidades tanto estatales, como acraestatales y privadas que prestan servicios de salud, observándose que hay un escaso grado de coordinación entre ellas y los Seguros Sociales, lo que deiermina en general duplicaciones en los gastos de administración y utilización deficiente de los recursos tanto humanos como físicos.

\section{La Seguriáad Social en el Perú}

La Conslitución dispone que la iey fijará las conaiciones de trabajo, indemnización por tiempo de servicios y por azcidenles, así como el eslablecimiento de un régimen de previsión de las consecuencias económicas de la desocupación, edad, enfermedad, invalidez y muerte.

En cumplimiento de lo que la Consítución dispone, se estableció por Ley $N^{\circ} 8433$, de 12 de agosto de 1936, el Sequro Social Obrero, quß en la aclualidad cubre los riesgos de Enfermedad, Maternidad e Invalidez. siendo obligatorio para obreros menores de 60 años de $\lesssim d a d$. Los riesgos de vejez y muerie se seporaron de la ley 8433 y se cubren cor el Fondo de Jubilación Obrera, ley 13640 de 21 de abril de 1961 . Los beneficios que la seguridad social otorga a los empleados públicos y pariiculares, se hallan contenidos en la ley 10902, del 19 de noviembre de 1948, que crea el Seguro Social del Empleado y que son la cobertura de los riesgos de Enfermedad, Mciernidad, Invalidez, Vejez y Muerie.

Los riesgos de accidentes del tracajo y enfermadad crotesional, tanto de emoleados como de obreros, están cubiertos por leyes aue garanlizarı sistemas especiales de compensación (Nos. 1378 de 1911 y 7975 de 1935 respectivamente).

Los efectivos de las fuerzas armadas y auxiliares gozan también de los beneficios de la seguridad social de acuerdo con sistemas privativos.

Otras leyes confieren beneficios sociales a determinados grupos de 'a población económicomente activa.

En 1964 la población económicamento activa representaba el $29 \%$ de la población total, los Seguros Sociales del Obrero y del Empleado 
cubrian 884,000 personas o sea el $27 \%$ de la población económicamente cctiva. El total de los empleados son cotizantes y deberían tener cubiertos sus riesgos, mientras que sólo el $17 \%$ de los trabajadores que pueden clasificarse como obreros están amparados por el Seguro Social Obrero. Desde su implantación el Seguro Social Obrero no ha ampliado practicamente su cobertura.

El sistema de financiamiento de los seguros es tripartito con aportes porcentuales, sobre sueldos y salarios, del empleador, del asegurado y del Estado.

Los riesgos cubiertos por los seguros son de dos tipos, unos relacionados con asignaciones y pensiones por riesgos de Invalidez, Vejez, Iubilación, Supervivencia y Muerte, y otros que se refieren a servicios de salud for riesgos de Enfermedad y Maternidad.

Las asignaciones y pensiones son administradas por el Fondo de Jubilación Obrera y por la Caja de Pensiones del Seguro Social del Empleado, según el caso.

\section{Rie.sgos Enfermedad-Maternidad}

Inicialmenta la atención médica de los riesgos de enfermedad y maternidad de la población económicamente débil ha sido de la competencia de las Beneficencias Públicas. Además, estas instituciones administraron y administran otros servicios de bien social como asilos para ancianos y para huértanos y están encargadas del gobierno de los cementerios.

No existe un organismo central directivo de las Beneficencias, de carácter nacional, constituyendo cada una de ellas una entidad autónoma local. Están regidas por un Directorio constituido por personas notables del lugar, en el que la autoridad sanitaria tiene la reoresentación del Minisierio de Salud Pública y Asistencial Social.

Se financian mediante recursos propios y subsidios del tesoro público. En el año 1964 han destinado 150 millones para gastos en salud de tipo reparativo, de los cuales 90 millones han sido transferidos por el Gobierno Central. Las Beneficencias Públicas contaron en 1964 con 84 hospitales y 8,974 camas que produjeron 99,000 egresos y l'400,000 consultas. La gran mayoría de estos locales de salud son vetustos y están pobremente dotados de equipo para una atención médica eficiente.

La población atendida por los servicios médicos de las Beneficencias está restringida al área urbana de las localidades en que están instclados. 
El Ministerio de Salud Pública y Asistencia Social tuvo su origen en la Dirección de Salubridad Pública, creada por Ley de 6 de noviembre de 1903, como dependencia del Ministerio de Fomento. En 1936 se creó el Ministerio de Salud Pública, Trabajo y Previsión Social; y, en 1942 tomó su actual denominación. Tiene a su cargo, por mandato constitucional. el cuidado de la salud pública y privada; establece la política nacional de salud a la cual deben sujetarse todos los organismos, tanto públicos como privados, que proporcionan servicios de salud y cumple iunciones normativas y ejecutivas de protección, promoción y recuperación de la salud.

Desde su creación el Ministerio de Salud Pública y Asistencia Social ha sufrido varias reorganizaciones, siendo la úitima la de 1965, que establece 2 niveles en su organización.

El Organismo Central, de carácter directivo, normativo, asesor, coor-

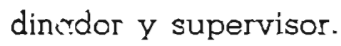

El Organismo Periférico, encargado de la ejecución de las acciones integradas de protección, promoción y recuperación de la salud.

Está financiado con fondos provenientes del tesoro público, e ingresos propios por venta de servicios, habiendo destinado en 1964, S/. l'093,000,000.00 a gastos en salud de tipo integrado preventivo-asistencial, de los cuales 576 millones se destinaron a reparación de la salud.

Las acciones de salud del Ministerio son heterogéneas y consecuミntemente es difícil señalar su cobertura. Algunas de las de tipo preventivo alcanzan la casi totalidad de la población nacional, otras como las reparativas tienen una cobertura compartida con los hospitales de las Beneficencias, alcanzando mancomunadamente la cifra estimada de 4'860,000 habitantes. Cuadro 3.

En 1964 el Ministerio contaba con 53 hospitales y 9,612 camas hospilalarias, 67 centros de salud, 210 Postas Médicas con 158 camas de reposo y otros establecimientos de menor importancia, y se produjeron 132,000 egresos y 3'600,000 consultas, aparte de actividades preventivas.

Las Sanidades de las Fuerzas Armadas y Auxiliares se crearon con la finalidad de prestar atención médica reparativa a los efeciivos del Ejército, Marina, Aeronáutica y Policía. Posteriormente los beneficios se extendieron a retirados y familiares de los efectivos. En ciertas localidades atienden a la población civil dentro de su programa de cooperación cívico-militar.

El comando de las acciones es ejercido por Direcciones de Sanidad integradas por profesionales médicos y paramédicos asimilados a las tuerzas armadas. 
Cuadro No 3. Población accesible a los Servicios de Salud y su Cobertura por Grupos de Entidades del Sector - 1964

\begin{tabular}{|c|c|c|c|c|}
\hline & & $\begin{array}{c}\text { No de ha- } \\
\text { bitantes }\end{array}$ & $\begin{array}{c}\% \text { pob. } \\
\text { total }\end{array}$ & $\begin{array}{c}\% \text { pob. } \\
\text { accsb. }\end{array}$ \\
\hline \multicolumn{5}{|c|}{ POBLACION ACCESIBLE: } \\
\hline (1) & $\begin{array}{l}\text { Cubierta por entidades de Se- } \\
\text { guridad Social }\end{array}$ & 884,000 & 8.3 & 11.6 \\
\hline (1) & $\begin{array}{l}\text { Cubierta por Sanidades de las } \\
\text { Fuerzas Armadas y Auxilares }\end{array}$ & 670.000 & 6.3 & 8.8 \\
\hline & $\begin{array}{l}\text { Cubierta por el Sector Pri- } \\
\text { vado }\end{array}$ & $1 ' 200,000$ & 11.2 & 15.7 \\
\hline \multicolumn{2}{|c|}{$\begin{array}{l}\text { (3) Cubierta por el Ministerio de } \\
\text { Salud Pública y A. S., Bene- } \\
\text { ficencia y otras }\end{array}$} & $4 ' 860,000$ & 45.3 & 63.8 \\
\hline \multicolumn{2}{|r|}{ TOTAL POBLACION ACCESIBLE } & $7^{\prime} 614,000$ & 71.0 & 100.0 \\
\hline \multicolumn{2}{|c|}{ POBLACION NO ACCESIBLE } & $3^{\prime} 109,000$ & 29.0 & \\
\hline \multicolumn{2}{|c|}{ POBLACION TOTAL } & $10^{\prime} 723,000$ & 100.0 & \\
\hline
\end{tabular}

(1) Información de las Oficinas de Programación

(2) Estimativa practicada en base a la razón población accesible en 1964 ;

egresos

7'614,000 hbts.

393,392 egresos

Egresos del Sector Privado en 1964: 62,000

(3) Establecido por diferencia 
Se financian por fondos del tesoro público, algunos impuestos con destino específico y recursos propios provenientes de la venta de servicios.

En el año 1964 se destinó la suma de S/. 238‘000,000.00 a gastos de reparación de la salud y algunas acciones de prevención.

Se estima en 670,000 personas la cobertura de las sanidades comprendiendo tanto a los efectivos, familiares, retirados y población rural aledaña a sus postas médicas. Cuadro № 3 .

Cuentan con 2,240 camas hospitaiarias repartidas en 9 hospitales; 43 Postas Médicas y 26 Enfermerías con $31 \mathrm{l}$ camas de $r=p o s o$.

En 1964 se produjeron 19,000 egresos y l'200,000 consultas.

El Seguro Social Obrero tuvo su origen en 1936 en la Ley 8433 que posteriormente sufre ampliaciones y modificaciones, hasta adquirir su configuración actual.

La Caja Nacional de Ssguro Social es el organismo de derecho público interno que, como entidad del Subsetcor Público Independiente, tiene a su cargo la formulación de la política de Seguridad Social para la población obrera del Perú y la Dirección de Prestaciones de Salud es la. Unidad Ejecutora de los programas de prestaciones frente a los Riesgos de Enfermedad, Maternidad e Invalidez.

Por mandato de la Lsy la cobertura de los Riesgos de Enfermedad y Maternidad se cumple a través de dos tipos de prestaciones: en especie y en dinero. En el Riesgo de Enfermedad las prestaciones $\in$ n especie consisten en atención médica general y especializada, servicios de hospitalización y servicios de Farmacia. Las prestaciones en dinero consisten en el olorgamiento de subsidios, como compensación del salario que el asegurado deja de percibir cuando está incapacitado para trabajar por adolecer de cualquier enfermedad no profesional o proveniente de accidente de trabajo, y cuyo monto asciende al $70 \%$ del salario del asegurado, pagándose a partir del tercer día de declarada la incapacidad. Cuando el asegurado se hospitaliza y no tiene carga familiar el subsidio se reduce a $35 \%$.

En el Riesgo de Maternidad, las prestaciones en especie consisten en alención médica general y especializada, servicios de hospitalización y servicio de Farmacia. Las prestaciones en dinero consisten en subsidios que se pagan a partir del $36^{\circ}$ día anterior al parto y que se extienden hasta el $36^{\circ}$ posterior al mismo, equivalente al $70 \%$ del salario promedio de la asegurada; y, además, en un subsidio de lactancia equivalente al $30 \%$ del salarjo de la as squrada y que se otorga durante los 240 primeros días de vida del hijo de la asegurada. 
El Seguro Social Obrero se finaricia con las cuotas de los asegurados, de los patronos y del Estado quienes, respectivamente, aportan el $3 \%, 6 \%$ y $2 \%$ del monto de las planillas de jormales; con el producto de las multas que se impongan por infracción de las Leyes rectoras del Seguro Social; con los intereses de sus capitales y reservas; con los legados y donaciones que se le hicieran y las herencias que se le dejaren; con un impuesto del $1 \%$ sobre el valor de las cancslaciones o pagos cue haga el Estado, los Concejos Municipales y las Compañias Fiscalizadas, con excepción de las servicios de las deudas externa $\theta$ interna, subvenciones a instituciones de beneficencia o de insirucción gratuita, emolumenlos, sueldos, pensiones y jornales; con un impuesto adicional $d=2 \%$ al tabaco y con un impuesto adicional de $2 \%$ al consumo de alcoholes y bebidas alcohólicas.

Del $11 \%$ a que asciende la cuota tripartita, se ha asignado actuarialmente el 6.3 para la cobertura de los Riesgos de Enfermedad Maternicad, asignación que se utjliza mediante el régimen de reparto anual y no se capitaliza.

Por mandato expreso de la ley, tanto las reservas técnicas como las reservas libres que se formen para los Riesgos de Invalidez, Vejez y Muerte, pueden ser invertidas dentro de las más eficientes condiciones de garantía y rentabilidad, prefiriéndose aquellas que reporien ventajas para los servicios de la institución, en beneficio de los asegurados, de la higiene social y la prevención de las enfermedades.

El monto total del gasto destinado a cubrir los riesgos de enfermedad y maternidad ascendió, en 1964, a S'. 530'000,000.00.

El Seguro Social Obrero en 1964, cubrió los riesgos de enfermedad y maternidad de 447, 427 osegurados activos.

En términos de recursos la Caja Nacional de Seguro Social cuenta con 13 Hospitales, 4 Policlínicos y 31 Postas Médicas, dolados con 2,767 camas para hospitalización, que produjeron en 1964, 53,000 egresos y 2'000,000 de consultas externas domiciliares, rurales y de emergencia.

El Seguro Social del Empleado se estableció, con carácter obliga1orio, por Decreto Ley N? 10902, de 19 de noviembre de 1948 para la protección del empleado público y particular en los riesgos de enfermedad, maternidad, invalidez, vejez y muerte, señalando que comprendería los casos no previstos por las leyes de jubilación, cesantía y montepio, y otras de previsión social vigentes sobre la misma materia.

Para cumplir con sus fines, el Seguro Social del Empleado ha sido organizado en base a un Consejo Superior que ejerce la dirección gene- 
ral y supervigilancia. Existen dos Cajas, de Enfermedad y Maternidad y de Pensiones. Las Cajas cuentan con sus propios Consejos, que emanan del Consejo Superior, y administran por separado cada Caja, le- niendo cada una su respectivo Gerente.

Los servicios comunes de ambas Cajas están administrados por el Gsrente General. La Inspección y Control la ejerce el Comité de Vigiiancia. Existe también en algunas localidades Consejos Locales con funciones especificas y limitadas.

El Consejo Superior está integrado por:

Un representante del Presidente de la República, quien lo preside: Diez delegados del Poder Ejecutivo designados en la siguiente forma:

Tres por el Ministerio de Trabajo y Asuntos Indígenas;

Tres por el Ministerio de Justicia y Culto; y,

Dos por cada uno de los Ministerios de Salud Pública y Asistencia Social y de Hacienda y Comercio.

Diez delegados de los asegurados.

Diez delegados de los empleadores particulares;

Tres delegados de las profesiones médicas; y el

Gerente General con derecho a voz.

Lo. Caja de Enfermedad-Maternidad es la entidad encargada por al Seguro de prestar al asegurado los siguientes beneficios:

1. Prestaciones en dinero:

a. Subsidios diarios de enfermedad;

b. Subsidios diarios de maternidad y lactancia; y

c. Asignación de sepelio.

2. Prestaciones asistenciales:

a. Atención médica general y especial y obstétrica;

b. Hospitalización, exámenes y tratamiento auxiliares y los demás que fueran menester;

c. Medicamentos esenciales y material indispensable de curación; y

d. Atención odontológica.

Los empleados particulares tienen derecho a todas las prestaciones en dinero y asistenciales.

Los emplados públicos tienen derecho a las prestaciones asistenciaies, al subsidio de lactancia y a la asignación de sepelio.

Tiene como organismo asesor normativo en asuntos técnicos, médicos y farmacológicos relacionados con lodos los tipos de servicios que otorga, a la Comisión Médica integrada en la siguiente forma: 
Un delegado que representa al Ministerio de Salud Pública y Asislencia Social en el Consejo Directivo, quien la preside:

El Director del Hospital Central;

El Asistente Técnico de la Dirección del Hospital Central;

El Jefe del Departamento de Control Médico:

Un representante de la Federación Médica Peruana;

Un representante del Colsgio Odontolćgico:

Un representante del Colegio de Químico-Farmacéuticos;

Un representante de los Cuerpos Médicos de los Hospitales del Seguro;

Un representante médico de los empleadores; y un representante médico de los asegurados.

Los representantes de los Colegios intervienen únicamente en los asuntos relacionados a su profesión.

Las prestaciones asistenciales, se otorgan mediante los s=rvicios propios de la Caja y por los servicios de hbre elección; brindándose a los asegurados los servicios médicos y paramédicos, en todo el territorio de la República.

La Caja de Pensiones es la entidad encargada por el Seguro de brindar al asegurado prestaciones de riesgo diferido que son las siquientes:

a. Pensiones de invalidez;

b. Pensiones de vejez;

c. Pensiones de jubilación:

d. Pensiones de sobrevivientes (viudez y orfandad);

e. Asignaciones de invalidez, vejez, muerte y capital de defunción.

Tienen derecho a estas prestaciones todos los empleados privados y los empleados públicos, que hubieran ingresado al servicio después de la dación de la ley en 1962, y aquellos que estando sujeios al ré gimen de jubilación, cesantia y montepío, hubieren aceptado este sistema cuando se inició $\leqslant l$ mismo.

Es necesario señalar que los pensionisias tienen derecho lambién a las prestaciones de enfermedad-maternidad.

Como existe la posibilidad de que una persona haya podido ser alternativamente obrero y empleado, la ley contiene dispositivos especiales para la coordinación de ambos seguros en lo que a este campo se refiere.

Esta Caja tiene como organismos asesores fundamentales, los Comités de Pensiones e Inversiones. 
En lo referente a la determinación del estado de invalidsz, para los fines de la asignación o pensión, según el caso, la Comisión Médica de la Caja de Enlermedad-Maternidad actúa como organismo dictaminante por disposición expresa de la ley.

Cada Caja tiene patrirnonio propio, constituido por las contribuciones de los asegurados, de los empleadores, y del Estado, las inversiones que efectúe conforme a Ley, el rendimiento de sus bienes, y las cportaciones voluntarias que reciba por cualquier concepto.

El régimen de contribuciones para las Cajas es el siquiente: Caja de Enfミrmedad-Maternidad.

a. Para los empleados particulares ( $7 \%$ del sueldo asegurable), en esta forma:

$3 \%$ a cargo del asegurado;

$3.5 \%$ a cargo del empleador; y

$0.5 \%$ a cargo del Estado.

b. Para los empleados públicos ( $6 \%$ del sueldo asegurable) en esta forma:

$2.5 \%$ a cargo del asegurado:

$3 \%$ a cargo del empleador; y

$0.5 \%$ a cargo del Eslado.

c. Para los asegurados tacultativos, su contribución será iqual a la cuota del asegurado más la del empleador, que se hubiere estado abonando.

El monlo de los haberes señalado para estos descuenios es un mínimo de 700 soles (en caso de ser el sueldo inferior, el empleado sólo paga el porcentaje que le corresponde, y el empleador la difierencia más su cuota patronal); el máximo es de S/. 7.000.00; toda cantidad que sxceda esta suma hasta!4,000.00 soles, está sujela al $2.1 \%$ de descuento. sea cual fuere la condición del empleado (público o privado).

\section{Caja de Pensiones}

Para los emplados privados y públicos, afectos a este régimena la contribución es del:

$1 \%$ a cargo del empleado;

$2 \%$ a cargo del empleador.

Estos montos pueden ser modificados si los egresos durante un año calendario sobrepasan a los ingresos. En este caso la contribución total se aumentará en $\mathrm{l}$ y $1 / 2 \%$. Además deben ser modificados a medida que las obligaciones de esta Caja aumentan. 
Como en toda institución de seguridad social, con el fin de estabilizar la situación financiera de las Cajas, éstas tienen un "fondo de reserva de seguridad", además del "fondo de patrimonio básico", al cual perienecen los inmuebles de las mismas.

El Seguro Social del Empleado cuenta con dos Hospitales y 1,350 camas, ubicados en Lima y Arequipa. Para cubrir los riesgos de Enfermedad y Maternidad en el resto del pais, el seguro ha establecido convenios con otras entidades como el Ministerio de Salud Pública y Asistencia Social, que cuenten con servicios médicos, para la atención de sus asegurados. Además existe el sistema de la libre elección del médico por el empleado.

En 1964 la cobertura del ssguro social del emplado fue de 436,661 personas. Se destinó S/. 596'000,000.00 a la atención de los riesgos Entermedad y Maternidad. Se produjeron 25,459 egresos y 688,000 consultas, en los servicios propios.

El Sector Privado está constituido por un complejo de inslituciones y servicios que cumplen distinta finalidad. En unos casos, como es el de los servicios médicos de las empresas agrícola y minera, se cumple con mandatos legales de indole social; en otros, como ocurre con los servicios de congregaciones religiosas, se expresa concretamente un ssntimiento filantrópico de asistencia social; y, finalmente, las clínicas y consultorios privados liene un carácter lucrativo.

En los dos primeros casos se cumple el objetivo de la seguridad social entendida como el socorro en situaciones emergentes de necesidad. En el tercer caso es sólo un servicio que se brinda a grupos económicamente solventes.

En el Sector Privado se distingue dos modalidades de organización:

10. La que podríamos denominar Institucionalizada (Hospitales, Clínicas, y Policlínicos); y

$2^{\circ}$ Los Consultorios Particulares.

E! Sector Privado tiene una financiación tan compleja como es su estructura. Es así como los servicios de las empresas agrícolas y mineras son finuncicidos cor los fondos de esas empresas. Los caritativos de las congregaciones religiosas tienen una doble fuente de financiamiento, fondos privados y subsidios estatales. El resto del sector, clínicas y consultorios cuentan con ingresos provenientes de su clientela.

En 1964, se estima que el Sector Privado proporcionó servicios de salud (predominantemente de reparación) por un valor de $\mathrm{S} /$. $905^{\prime} 000,000.00 \mathrm{sin}$ incluir gastos en medicamentos que se estiman en S/. 300'000,000.00. Además, el Sector Privado contó con 3,594 comas- 
hospitalarias en 115 hospitales, y se produjeron 62,000 egresos; aproximadamenle el $28 \%$ de las horas-médico disponibles en el país se dedican a la práctica privada habiéndose brindado alrededor de 7 millones de consultas médicas y 3 millones da consultas dentales. La cobertura estimada para el Sector Privado es de 1'200.000 personas. Cuadro № 3 .

El riesgo de accidentes del trabajo que no es cubierto por los Seguros Sociales se atiende por las Compañias privadas de Seguros, a cuenta del empleador.

\section{Mecanismo de Coordinación}

Existe una estructura orgánica encargada de la coordinación tanto inter como intrasectorial. De ella forman parte órganos coordinadores en los niveles nacional y local, en los que el Ministerio de Salud Pública y Asistencia Social está representado. En el nivel nacional existen: El Consejo Nacional de Desarrollo Económico y Social, entidad integrante del Sistema Nacional de Planificación, encargado de dar las orientaciones fundamentales al proceso de la Planificación, formulando la política de desarrollo económico y social del gobiemo; la Dirección de Planificación Sectorial, dependencia del Instituto Nacional de Planificación, que coordina los planes de los diferentes sectores: Comisiones Interministeriales para planes específicos de desarrollo, tales como las de la Carretera Marginal de la Selva, Reforma Agraria e Integración de la Población Aborigen.

A nivel local existen: El Comilé de Coordinación, órgano intersectorial presidido por la más alta autoridad política local, encargado de coordinar las actividades del sector público; Comisiones para la ejecución de programas de desarrollo en que participan representantes de las distintas entidades del Sector Público, Coordinaciones Departamentales de Alimentación, encargadas de ejecutar un programa de salud con la cooperación de entidades públicas y privadas locales.

Todas las entidades señaladas estarían encargadas de la coordinación intersectorial.

Para la coordinación intrasectorial se cuenta igualmente con órganos tanto de nivel nacional cuanto local, distinguiéndose, entre los primeros, los siguientes: El Consejo Nacional de Salud, organismo asesor del Despacho Ministerial en lo que respecta a los próblemas de salud nacionales. Es presidido por el Ministro de Salud Pública y Asistencia Social e integrado por otros 13 miembros entre los que figuron el 
Gerente General del Seguro Social del Empleado y el Director Gerente de la Caja Nacional de Seguro Social (Obrero); el Comité Asミsor de la Oficina Sectorial de Planificación, presidido por el Director de la Sectorial e integrado por representantes de las entidades públicas y privadas del Sector y cuya finalidad es coordinar la participación de las instituciones representadas en el proceso de planificación. Ambos Seguros están representados por los Jeles de sus respectivas Oficinas de Programación; la Representación del Ministerio de Salud Pública y Asistencia Social en los Directorios o Consejos Superiores de las entidades del Sub-Sector Público Independiente, entre las que figuran los Seguros Sociales del Empleado y Obrero. (En el primero hay dos representantes del Ministerio en su Consejo Superior, uno de los cuales preside la Comisićn Médica, que es asesora de la Caja de Enfermedad-Maternidad. En el Consejo Directivo dsl Seguro Obrero el Ministro de Salud Pública y Asistencia Social es presidente y el Director General de Salud es uno de los miembros).

A nivel local la coordinación intrasectorial se realizaría mediante:

Representación del Ministerio de Salud Pública y Asistencia Social en los Directorios de las Sociedades de Beneficencias Públicas y da las Juntas de Obras Públicas y Corporaciones de Saneamiento; y Comités de Coordinación de las Areas y Unidades de Salud, encargados de orientar y coordinar las actividades de las Instituciones públicas y privacias que ejecuton acciones de salud.

En realidad, todos estos mecanismos de coordinación o no funcionan en la práctica o lo hacen deficientemente.

Enjuiciamienlo de la situación.

La atención de los "estados de necesidad" de la colectividad nacional se hace en la actualidad a través de diversos organismos públicos, tanto por los denominados Seguro Social Obrero y Seguro Social del Empleado, cuanto por otras entidades como el Ministerio de Salud Pública, las Beneficencias y las Sanidades de las Fuerzas Armadas.

Enjuiciaremos en particular la atención de los riesgos de enfermedad-maternidad. Aproximadamente sólo el $70 \%$ de la población tendría posibilidad de ser atendido por los servicios $p \equiv$ rmanentes de salud, por el hecho de residir en lugares donde existen estos servicios. El 30\% restante, constituido, fundamentalmente, por población rural, está marginado del sistema. Los beneficios otorgados son muy desiguales y así tenemos que, por ejemplo, los grupos asegurados reciben servicios de 
atención médica ,odontológica, hospitalización y farmacia, equ!valentes a un gasto per cápita de S/. 1,274.00 al año, (sın incluir subsidios) mientras que los grupos atendidos por el Ministerıo d ミ Salud Púb!ica y Asistencia Social y las Beneficencias, reciben servicios equivalentes a un gasto anual per cápita de S/. 239.00 Cuadro N! 4.

Como conclusión, podemos afirmar que los asegurados constituyen un grupo minoritario privilsgiado mientras que, simultáneamente, hay una mayoria de la población cuyas necesidades en salud son atendi-

Cuadro No 4. Gasto anual Per/Cápita en salud por entidades del sector 1964

\begin{tabular}{|c|c|c|c|}
\hline Entidades & $\begin{array}{c}\text { Población } \\
\text { Accesible } \\
\text { Cubierta }\end{array}$ & $\begin{array}{l}\text { Gastos en } \\
\text { Millones } \\
\text { de soles }\end{array}$ & $\begin{array}{c}\text { Gasto } \\
\text { Anual } \\
\text { Per/Cápita }\end{array}$ \\
\hline SEGURIDAD SOCIAL & 884,000 & $1,126^{\prime} 000$ & 1,274 \\
\hline Seguro Social Obrero & 447,000 & $530^{\prime} 000$ & 1,186 \\
\hline Seguro Social Empleado & 437,000 & $596 ’ 000$ & 1,364 \\
\hline SANIDADES DE LAS FUERZAS & & & \\
\hline ARMADAS & 670,000 & $238^{\prime} 000$ & 355 \\
\hline SECTOR PRIVADO & $1 ' 200,000$ & 905,000 & 756 \\
\hline MINISTERIO DE SALUD PU- & & & \\
\hline BLICA Y BENEFICENCIAS & $4^{\prime} 860,000$ & $1,163^{\prime} 000$ & 239 \\
\hline TOTAL & $7^{\prime} 614,000$ & $3,432^{\prime} 000$ & 451 \\
\hline
\end{tabular}

(1) Excluidos gastos de inversión

(2) Excluidos gastos de actividades de promoción y protección de salud.

das en condiciones muy inferiores y que, practicamente, un $30 \%$ de la población no recibe ningún tipo de atención.

Los servicios de salud que se brindan en el pais, especialmente en el grupo asegurado, son fundamentalmente de carácier asistencial y orientados al individuo, a diferencia de las acciones preventivas, a cargo del Ministerio de Salud Pública, que thenen como sujeto a la familia. Los seguros sociales, con su orientación individualista, tienen pocas posibilidades de ejecular acciones preventivas que reducirian los riesgos que alienden. Si bien es cierlo que el Ministerio de Salud Pública y Asislencia Social realiza acciones preventivas, éstas aún no han alcanzado una cobertura suficiente, salvo algunas excepciones. 
La existencia de varias entidades que prestan servicio de salud; con autonomía suficiente para formular su propia política y con clientelas muy definidas, determina que haya duplicación en gastos de administración, deficiente utilización de los servicios, que se manifiesta en ei escaso rendimiento de las camas hospitalarias, (en 1964, se produjeron 13.6 egresos for cama hospitalaria del sector público, pudiendo considerarse como una producción normalizada, 18 egresos) y el escaso rendimiento de la hora-médico que se ha calculado en 2.91 consultas por hora, habiéndose estimado como norma 6, todo lo cual significa una baia productividad del sistema.

Gráfico No I Porcentajes de pohración accesible cubierta y de gastos en salur por entidares del sector - 1964

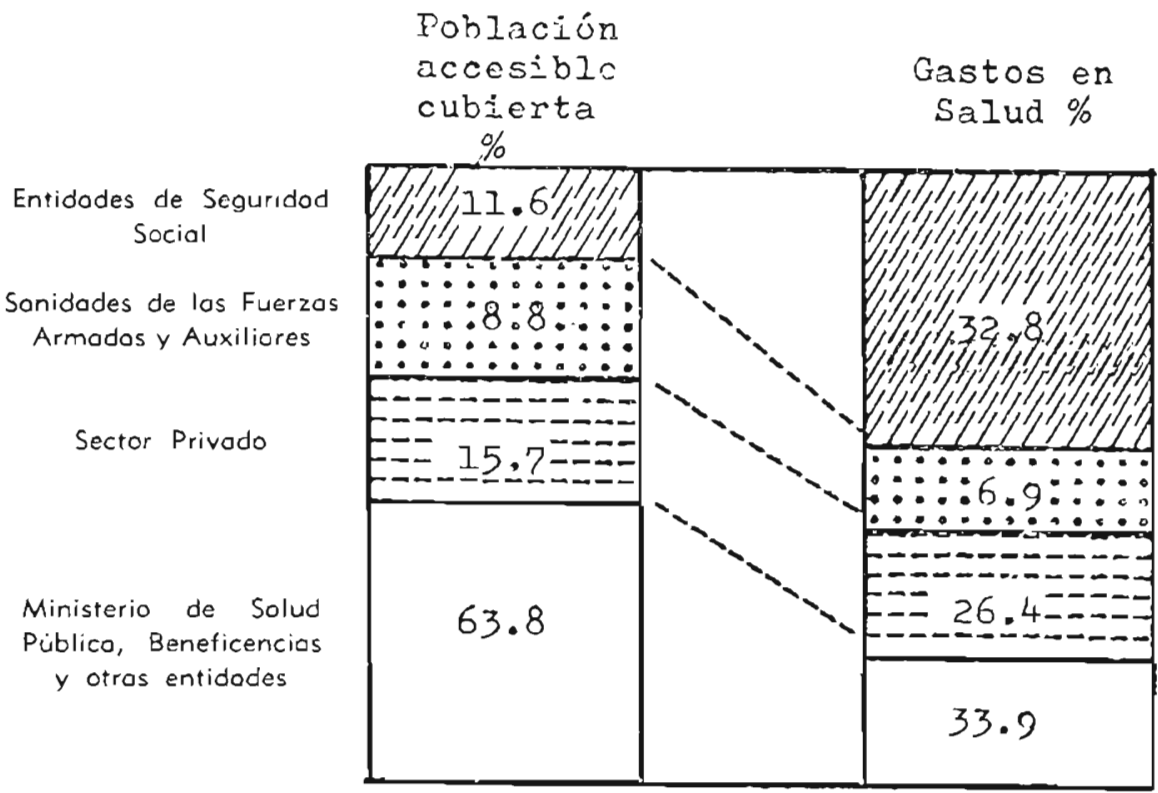

El financiamiento de los servicios proporcionados por el Ministerio y las Beneficencias se hace fundamentalmente con impuestos generales, aportados por toda la colectividad y como dichos servicios se orientan a los grupos de menores recursos tiensn un efecto progresivo en la distribución del ingreso. No ocurre lo mismo con las Sanidades de las Fuerzas Armadas, las que se financian principalmente con impuestos gene- 
rales mientras que los bミneficios son otorgados en particular a los efeclivcs, sus familiares y a los retirados.

La ínanciación tripartita de los Seguros Sociales es una realidad cuya vigencia no resiste el más superíicial análisis. Electivamente, la contribución del empleador e incluso la del empleado, en cierta forma es rescatada mediante una elevación en el costo del croduclo que debe sufragar toda la ciudadanía, asegurada y no asegurada, y el apcrte es. tatal se resarce a través de gravámenes, por lo común indırectos, que igualmente afectan al total de la ciudadanía. Ambos mecamsmos de defensa, tanto el del empleador como el del Estado, son factores condicionantes de inflación, el primero, por slevación del costo de los bienes de consumo y el otro, por disminuir la capacidad adquisitiva del contribuyente. Finalmente, resulta injusto que un sistema realmente financiado por el pueblo en general, beneficie sólo a una clase en particular, siendo sus efectos en la distribución del ingreso de carácler regresivo.

Si bien existen formalmente mecanismos de coordinación inter e intrasectorial, tanto a nivel nacional como local, en realidad dichos mecanisinos no funcionan, dándose el caso de que algunos de ellos no se han consítuido en la práctica. Esta situación determina un escaso grado de coordinación que sumado a la autonomía de las entidades del Sector para su propio gobierno, es causa principal de la inexisiencia de una política de salud compatible con la satisfacción de las necesidades de este campo.

Pensamos que un servicio único de salud sería benéfico pues facilitaria la cocrdinación y reduciría los gasios de administración.

\section{Recomendaciones}

1. La atención ds los esiados de necesidad debe quardar cierta relación con el grado de descrrollo económico y social de las colectividades, ya que se reconoce que los excesivos beneficios sociales entraban el desarrollo, al desalentar las inversiones. Por otra parte, no disen circunecribirse a grupos minoritarios, por el contrario deben ampliarse a toda le colectividad.

2. La seguridad social debe tener como basamento la unsticia distributiva, corolario de la solidaridad humana, que se traduce por una más alta contribución de los grupos de mayores ingresos, sufragando el gasto en servicios públicos en forma progresiva a sus ingresos, debiendo los beneficios ser uniformes para las distintas capas sociales. Podrian establecerse beneficios agregados mediante aportes individuales extraor- 
dinarios y voluntarios para aquellos que disponen de más recursos y tienen capacidad de ahorro, para lo cual podría estimularse la iniciativa privoda en la previsión de servicios de salud. Lo expuesto exigirá una reforma tributaria orientada a la imposición directa y progresiva.

3. Los servicios de atención de los riesgos de Enfermedad y Maternidad requieren de una política administrativa uniforme, cuya tecnología difiere de la administración de los riesgos diferidos.

4. Los servicios de salud deben prestarse en forma integrada y al grupo familiar, lo que requiere la fusión $\mathrm{d}=$ recursos en una entidad única.

El esfuerzo de las acciones preventivas que implícitamente conllevan tanto la extensión al grupo familiar, cuanto la creación de un órgano único, reduciria, por lo menos, los riesgos de entermedad, lo que significaría reducción en los gastos de reparación cuyo costo es creciente.

5. La dación de una Ley Orgánica de Salud facilitaría la delimitaciór de los campos público y privado y cermitiria el establecirniento de una política sectorial enmarcada dentro de la política general de desarrollo, que oriente los planes de desarrollo económico y social.

6. I_a extensión de los beneficios sociales debき ser estudiada cuiáadosamente por técnicos que tomen en consideración todos sus aspectos, evitándose el vicio de utilizarlos como armas de la demagogia o de fresión de grupos económica y politicamente poderosos.

A través de lo expuesto es fácil daducir el grave daño que causan a la economia nacional y lo injusto que resultan para la gran masa de la población más necesitada.

\section{BIBLIOGRAFIA}

Ofucina Sanitaria Panamericana. Grupo de Estudio soble Coordinación de la Atención Médica de América Latina. Julio de 1965.

Dr. Benjamin Viel. La Medicina Socializada. 1961.

Unión Panamericana. Extensión de la Seguridad Social a las Zonas Rurales.

Aníbal Pinto. Alternativa para una reforma de los sistemas convencionales de previsión social.

Oficina Sectorial de Planificación de Salud. Diagnóstico de la Situación de Salud. Perú 1966.

Servicio Cooperativo del Empleo del Perú. Síntesis de la Legislación del Trabajo del Perú. 1962. 